\title{
Evidence for an association between infant mortality and homozygosity for the arctic variant of carnitine palmitoyltransferase $1 \mathrm{~A}$
}

\author{
Bradford D. Gessner, MD, MPH ${ }^{1,4}$, Thalia Wood, $\mathrm{MPH}^{1,4}$, \\ Monique A. Johnson, $\mathrm{PhD}^{2}$, Carolyn Sue Richards, $\mathrm{PhD}^{2}$ and David M. Koeller, $\mathrm{MD}^{2,3}$
}

Purpose: Infant mortality in Alaska is highest among Alaska Native people from western/northern Alaska, a population with a high prevalence of a genetic variant (c.1436C $>\mathrm{T}$; the arctic variant) of carnitine palmitoyltransferase 1A (CPT1A).

Methods: We performed an unmatched case-control study to determine the relationship between the arctic variant and infant mortality. The cases were 110 Alaska Native infant deaths from 2006 to 2010 and the controls were 395 Alaska Native births from the same time period. In addition to the overall analysis, we conducted two subanalyses, one limited to subjects from western/northern Alaska and one limited to infants heterozygous or homozygous for the arctic variant.

Results: Among western/northern Alaska residents, 66\% of cases and $61 \%$ of controls were homozygous (adjusted odds ratio (aOR): 2.5; 95\% confidence interval (CI): 1.3, 5.0). Among homozygous or heterozygous infants, $58 \%$ of cases and $44 \%$ of controls were homozygous (aOR: 2.3; 95\% CI: 1.3, 4.0). Deaths associated with infection were more likely to be homozygous (OR: 2.9 ; 95\% CI: $1.0-$ 8.0). Homozygosity was strongly associated with a premorbid history of pneumonia, sepsis, or meningitis.

Conclusion: Homozygosity for the arctic variant is associated with increased risk of infant mortality, which may be mediated in part by an increase in infectious disease risk. Further studies are needed to determine whether the association we report represents a causal association between the CPT1A arctic variant and infectious diseasespecific mortality.

Genet Med advance online publication 28 January 2016

Key Words: Alaska Native; carnitine palmitoyltransferase 1A; fatty acid oxidation; infant mortality; indigenous populations

\section{INTRODUCTION}

The severe form of carnitine palmitoyltransferase 1A (CPT1A) deficiency is a rare autosomal recessive disorder of fatty acid oxidation that results from nearly complete loss of enzyme activity, which impairs fasting ketogenesis and gluconeogenesis. Symptoms include hypoketotic hypoglycemia and liver failure. We and others have described a nonsynonymous DNA sequence variant of CPT1A (rs80356779; c.1436C $\rightarrow$ T; p. P479L) that is highly prevalent among indigenous Arctic peoples of Alaska, Canada, Greenland, and northeast Siberia. ${ }^{1-5}$ Within these populations, the variant allele is the most common, with an allele frequency ranging from 0.68 to 0.85 . We have named this variant the arctic variant, consistent with its primary distribution within indigenous arctic populations of Alaska, Canada, Greenland, and Siberia. ${ }^{1,3,4}$ However, it is also common among indigenous inhabitants of coastal British Columbia. ${ }^{6}$ The arctic variant results in only a partial loss of CPT1A activity; nonetheless, fasting ketogenesis is significantly impaired in young children homozygous for the variant. ${ }^{7}$

Fatty acid oxidation disorders, including CPT1A deficiency, are known to increase the risk of sudden unexpected infant death. ${ }^{8}$
In Alaska, infant mortality rates are higher in Alaska Native peoples. The highest rates are among the Yup'ik and Inupiat people residing in western and northern Alaska, where the highest prevalence of the arctic variant in Alaska has been observed. ${ }^{3,9-12}$ The current study was undertaken to more definitively evaluate our preliminary observation of an association between the arctic variant and infant mortality risk among Alaska Native people. ${ }^{13}$

\section{Study design}

\section{MATERIALS AND METHODS}

To test the hypothesis that homozygosity for the arctic variant is a risk factor for infant death, we performed an unmatched case-control study that included all infant deaths among Alaska Native children born from 2006 to 2010. This time period was chosen based on the availability of newborn screening cards. We limited the study population to Alaska Native infants based on previous studies in which we demonstrated that the arctic variant occurs almost exclusively among Alaska Native people. ${ }^{3}$ Alaska Native status was defined as having either the mother or the father self-identify as Alaska Native race on the infant's birth certificate.

\footnotetext{
${ }^{1}$ Alaska Division of Public Health, Anchorage, Alaska, USA; ${ }^{2}$ Department of Molecular and Medical Genetics, Oregon Health \& Science University, Portland, Oregon, USA;

${ }^{3}$ Department of Pediatrics, Oregon Health \& Science University, Portland, Oregon, USA; ${ }^{4}$ Present address: EpiVac Consulting, Anchorage, Alaska, USA (B.D.G); Association of Public Health Laboratories, Silver Spring, Maryland, USA (T.W.). Correspondence: David M. Koeller (koellerd@ohsu.edu)
}

Submitted 17 July 2015; accepted 17 November 2015; advance online publication 28 January 2016. doi:10.1038/gim.2015.197 
We utilized an unmatched case-control design with a 1:3 case-to-control ratio. Using a linked birth and death certificate file from the Alaska Bureau of Vital Statistics, we included as cases 150 Alaska Native infants who died before 1 year of age from the beginning of 2006 to the end of 2010. We selected controls by ordering all Alaska Native births during the study period and using a random number generator to select 450 infants. The random number generator did not select any cases as controls.

We were able to locate newborn screening cards for 110 (73\%) of the 150 cases and 395 (88\%) of the 450 controls. Newborn screening cards were unavailable if death occurred before screening was performed or if high-risk mothers and critically ill newborns were transferred to hospitals outside of Alaska; these factors may have differentially affected our ability to identify newborn screening cards from infants who died versus control infants. In addition, names may have changed after birth, making it difficult to link a birth certificate to the screening card, and cards may have been misplaced. Our sample size gave us $80 \%$ power to detect an odds ratio of approximately 2.0 at the $95 \%$ confidence level.

\section{Genotype analysis}

Genotyping was performed by the Molecular Diagnostic Center at Oregon Health \& Science University using DNA isolated from newborn screening cards via an allelic discrimination assay originally developed for clinical testing. ${ }^{3}$ Samples were coded with a unique identifier and tested anonymously, including masking of the case or control status of the samples. We defined the wild-type allele (c.1436C) as that corresponding to the National Center for Biotechnology Information reference sequence for CPT1A (NM_001876.3), recognizing that within some Alaska Native populations the variant allele (c.1436T) is the wild type.

\section{Data analysis}

Our initial analysis included study infants of all genotypes from all regions of Alaska. To account for geographic differences in the prevalence of the arctic variant and potential geographic variability of known risk factors for infant mortality, we performed two additional analyses. The first included infants from all regions of Alaska but was limited to those who were either homozygous or heterozygous for the arctic variant. The second was limited to study infants residing in western and northern Alaska, regardless of genotype, based on previous results indicating that the prevalence of the CPT1A arctic variant was highest in these regions. ${ }^{3}$ For each analysis, we created logistic regression models that included mortality as the dependent variable and CPT1A genotype (for the first, either homozygous or heterozygous; for the second, homozygous or nonhomozygous) as the primary independent variable of interest. Adjustments were made for three potentially confounding variables that we previously identified to be associated with risk of infant mortality: maternal prenatal alcohol or tobacco use, maternal education, and a composite variable reflecting the involvement of a father figure. ${ }^{14}$ The latter was created using birth certificate variables for marital status and father's name, with the following three categories: married, not married and father's name present, and not married and father's name absent. Birth weight and preterm birth were not included as independent variables because they are potentially intermediate outcomes related to the final outcome measure (i.e., death) and controlling for them could bias our results. ${ }^{15-17}$ Nevertheless, we conducted a separate set of analyses limited to infants with normal birth weight (2,500 $\mathrm{g}$ or greater).

Data regarding each case were collected from medical records housed at the Alaska Division of Public Health $(\mathrm{AKDPH})$ as part of the Maternal-Infant Mortality Review and included maternal and infant medical records, birth and death certificates, autopsy reports, first-responder reports, and child protective services reports. Data were abstracted using a standardized form by experienced abstracters who were blinded to the genotype of the infant.

\section{Study oversight}

The newborn screening panel used in Alaska includes all of the core conditions and secondary targets recommended by the American College of Medical Genetics and Genomics, ${ }^{18}$ including CPT1A deficiency. In collaboration with the AKDPH, we have shown that the current method of newborn screening used to identify infants homozygous for the arctic variant has low sensitivity. ${ }^{3}$ The current evaluation was performed, in part, to collect data on the clinical consequences of the arctic variant to inform the Alaska Newborn Metabolic Screening Program regarding whether increased ascertainment of infants homozygous for the CPT1A arctic variant by newborn screening could potentially lead to improved health outcomes. The use of newborn blood spots for this evaluation was approved by the AKDPH Newborn Metabolic Screening Advisory Committee. The study was approved by expedited review and granted a waiver of informed consent for use of the dried blood spots by the Institutional Review Board of Oregon Health \& Science University. This article was reviewed and approved by the Alaska Native Tribal Health Consortium Health Research Review Committee prior to submission for publication.

\section{RESULTS}

\section{Characteristics of study population}

There were significant differences between cases and controls in several variables known to be associated with risk of infant mortality, including involvement of a father figure $(P<0.001)$, maternal prenatal alcohol or tobacco use $(P=0.001)$, preterm birth $(<32$ weeks $)(P<0.001)$, and low birth weight $(<1,500 \mathrm{~g})$ $(P<0.001)$ (Table 1$)$. Maternal education differed between the two groups but did not reach statistical significance $(P=0.08)$. The overall distribution of genotypes was not significantly different between cases and controls $(P=0.06)$, but infants who died were more likely to be homozygous for the arctic variant (42 vs. $30 \%)$. 


\section{Associations between the CPT1A arctic variant and infant mortality}

Homozygosity for the arctic variant was associated with infant mortality in all analyses (Table 2). When infants of all birth weights were included, the association was strongest among residents of western and northern Alaska. Exclusion of low-birth-weight infants led to similar results. Of the 46 deaths in infants homozygous for the arctic variant, the mean gestation was 37 weeks (median: 38 weeks; range: 21-42 weeks) and the mean birth weight was $3,146 \mathrm{~g}$ (median: 3,317; range: 566-5,361).

Within the overall study population, both birth weight and gestation were significantly lower among infants who died than in control infants (Table 1). The average age at death was 96 days (median: 82 days; range: 0-306 days); two deaths (4\%) occurred at less than 1 week of age and 10 (22\%) occurred during the neonatal period (age $<28$ days). Eighteen deaths (39\%) occurred at home, 16 (35\%) occurred in the hospital, 7 (15\%) occurred in the emergency room or as an outpatient, and the remaining $5(11 \%)$ occurred in a variety of other settings.

\section{Association between the CPT1A arctic variant and cause of death}

Allowing for multiple causes of deaths, the contributing or underlying cause was categorized as sudden infant death syndrome (SIDS) or asphyxia of unknown etiology for 44 of the

Table 1 Characteristics of the study population

\begin{tabular}{|c|c|c|c|c|}
\hline Characteristic & & $\begin{array}{c}\text { Cases } \\
(N=110)\end{array}$ & $\begin{array}{l}\text { Controls } \\
(N=395)\end{array}$ & $\begin{array}{l}\text { Chi-square } \\
\text { ( } P \text { value })\end{array}$ \\
\hline \multirow[t]{3}{*}{ Genotype } & Homozygous variant & $46(42 \%)$ & $119(30 \%)$ & $5.5(0.06)$ \\
\hline & Heterozygous & $33(30 \%)$ & $150(38 \%)$ & \\
\hline & Homozygous wild type & $31(28 \%)$ & $126(32 \%)$ & \\
\hline Residence in western/northern Alaska & & $58(53 \%)$ & $185(47 \%)$ & $1.2(0.27)$ \\
\hline \multirow[t]{3}{*}{ Involvement of father } & Married & $24(22 \%)$ & $135(34 \%)$ & $26(<0.001)$ \\
\hline & $\begin{array}{l}\text { Unmarried: father's name on } \\
\text { birth certificate }\end{array}$ & $48(44 \%)$ & $206(52 \%)$ & \\
\hline & $\begin{array}{l}\text { Unmarried: father's name not on } \\
\text { birth certificate }\end{array}$ & $38(35 \%)$ & $54(14 \%)$ & \\
\hline Maternal prenatal alcohol/tobacco use & & $63(57 \%)$ & $156(40 \%)$ & $12(0.001)$ \\
\hline \multirow[t]{3}{*}{ Maternal education } & $<12$ years & $37(35 \%)$ & $96(25 \%)$ & $5.0(0.08)$ \\
\hline & 12 years & $55(52 \%)$ & $225(58 \%)$ & \\
\hline & $>12$ years & $13(12 \%)$ & $67(17 \%)$ & \\
\hline Female & & $53(48 \%)$ & $207(52 \%)$ & $0.6(0.43)$ \\
\hline \multirow[t]{3}{*}{ Gestational age } & $<32$ weeks & $11(10 \%)$ & $3(0.8 \%)$ & $31(<0.001)$ \\
\hline & 32-36 weeks & $17(16 \%)$ & $39(10 \%)$ & \\
\hline & $37+$ weeks & $81(74 \%)$ & $350(89 \%)$ & \\
\hline \multirow[t]{3}{*}{ Birth weight } & $<1,500 \mathrm{~g}$ & $8(7 \%)$ & $2(0.5 \%)$ & $23(<0.001)$ \\
\hline & $1,500-2,499 \mathrm{~g}$ & $8(7 \%)$ & $15(4 \%)$ & \\
\hline & $2,500+g$ & $94(86 \%)$ & $377(96 \%)$ & \\
\hline
\end{tabular}

Table 2 Association between homozygosity for the arctic variant of CPT1A and infant mortality

\begin{tabular}{|c|c|c|c|c|c|}
\hline \multirow[b]{2}{*}{ Analytic subgroup } & & \multicolumn{2}{|c|}{$\begin{array}{l}\text { Rate of homozygosity } \\
\text { for the arctic variant }\end{array}$} & \multirow{2}{*}{$\begin{array}{l}\text { Odds ratio } \\
(95 \% \mathrm{Cl})\end{array}$} & \multirow{2}{*}{$\begin{array}{c}\text { Adjusted }^{a} \\
\text { odds ratio } \\
(95 \% \mathrm{Cl})\end{array}$} \\
\hline & & Cases & Controls & & \\
\hline \multirow[t]{3}{*}{ All birth weights } & All subjects ${ }^{b}$ & 46 of $110(42 \%)$ & 119 of $395(30 \%)$ & $1.7(1.1,2.6)$ & $1.8(1.1,2.9$ \\
\hline & Homozygous or heterozygous variant ${ }^{c}$ & 46 of $79(58 \%)$ & 119 of $269(44 \%)$ & $1.8(1.1,2.9)$ & $2.3(1.3,4.0)$ \\
\hline & Residents of western and Northern Alaskab & 38 of $58(66 \%)$ & 112 of $185(61 \%)$ & $1.8(0.98,3.3)$ & $2.5(1.3,5.0$ \\
\hline \multirow[t]{3}{*}{ Birth weight $\geq 2,500 \mathrm{~g}$} & All subjects ${ }^{b}$ & 39 of $94(41 \%)$ & 112 of $377(30 \%)$ & $1.7(1.1,2.7)$ & $1.8(1.1,2.9$ \\
\hline & Homozygous or heterozygous variant ${ }^{c}$ & 39 of $69(57 \%)$ & 112 of $258(43 \%)$ & $1.7(0.99,2.9)$ & $2.2(1.2,3.9$ \\
\hline & Residents of western and Northern Alaskab & 33 of $48(69 \%)$ & 88 of $154(57 \%)$ & $2.2(1.1,4.2)$ & $3.0(1.4,6.3)$ \\
\hline
\end{tabular}

aAdjusted for maternal education, maternal prenatal alcohol and tobacco use, and a composite variable combining marital status and presence of the father's name on the birth certificate. bor these analyses, cases and controls were classified as either homozygous or nonhomozygous variant. 'For these analyses, cases and controls were classified as either homozygous or heterozygous variant. 
110 deaths (40\%), congenital anomalies were the cause of 20 (18\%), infection was the cause of $19(17 \%)$, and trauma or injury was the cause of $11(10 \%)$ (Table 3). Less frequent causes included perinatal events $(n=4)$, drug exposure $(n=4)$, abuse or neglect $(n=3)$, preterm birth $(n=1)$, and other or unknown $(n=10)$. Of the 46 deaths among infants homozygous for the arctic variant, $14(30 \%)$ were associated with SIDS/asphyxia of unknown etiology; 12 (26\%) with infection; 8 (17\%) with congenital anomalies; 5 (11\%) with injuries; $3(7 \%)$ with perinatal events; 1 each (2\%) with preterm birth, abuse, or neglect; and 2 each (4\%) with other causes or unknown cause. These data demonstrate an association between homozygosity for the arctic variant and death associated with infectious diseases (OR: 2.9; 95\% CI: 1.0, 8.0). By contrast, infants homozygous for the arctic variant were underrepresented among deaths attributed to SIDS/asphyxia of unknown etiology (OR: 0.5; 95\% CI: $0.22,1.1$ ).

\section{Association between the CPT1A arctic variant and health history}

Using records in the Alaska Maternal-Infant Mortality Review Program we used a standardized form to abstract data from pediatric medical records regarding health history before the illness or event(s) leading to death for infants who died. We identified pediatric medical records for 107 of the 110 infant deaths, and these children formed the study cohort for this analysis. Among infants who died, those who had experienced any previous hospitalization, pneumonia, or episode of sepsis or meningitis were substantially more likely to be homozygous than nonhomozygous for the arctic variant (Table 4). Homozygosity for the arctic variant was not associated with medical record history of any other clinical outcomes that were evaluated, which included maternal complications (chorioamnionitis), problems during the newborn period (meconium aspiration, necrotizing enterocolitis, hypoglycemia, respiratory distress syndrome, anemia, and jaundice), and postnewborn maladies (gastroenteritis, anemia, and dehydration). Lack of an association between prior outcomes and CPT1A genotype does not imply that these events were not present at the time of death. For example, hypoglycemia may have been present at death even though we found no increase in risk of hypoglycemia before the events leading to death.

\section{DISCUSSION}

Previous work in Alaska has identified three variables that account for most of the differences in postneonatal infant mortality rates between Alaska Native and non-Native persons: maternal education, maternal prenatal substance use, and a proxy measure for involvement of a father figure. ${ }^{14}$ However, after adjusting for the presence of these factors, the likelihood of infant mortality among Alaska Native infants is still higher (OR: 1.3; 95\% CI: 1.1-1.6), indicating the presence of additional unidentified risk factors. Within our study population, which was limited to Alaska Native infants, we observed the expected association of these previously identified risk factors and infant death (Table 1). In addition, we identified another risk factor, namely, homozygosity for the CPT1A arctic variant.

The Yup'ik and Inupiat people are the primary Alaska Native residents of the northern and western regions of Alaska, where the prevalence of the arctic variant and infant mortality rates are highest. ${ }^{3}$ Among Alaska Native children born during 2006-2010, the infant mortality rate in the western and northern regions was 13.9 per 1,000 live births compared with 8.7 for the remainder of the state (rate ratio: 1.6; 95\% CI: 1.2-2.1)

Table 3 Association between the arctic variant of CPT1A and cause of death

\begin{tabular}{|c|c|c|c|}
\hline \multirow[b]{2}{*}{ Cause of death } & \multicolumn{2}{|c|}{ Genotype } & \multirow[b]{2}{*}{ Odds ratio $(95 \% \mathrm{Cl})$} \\
\hline & $\begin{array}{l}\text { Homozygous variant } \\
\qquad(n=46)\end{array}$ & $\begin{array}{l}\text { Heterozygous or homozygous } \\
\text { wild type }(n=64)\end{array}$ & \\
\hline $\begin{array}{l}\text { Sudden infant death syndrome or asphyxia of } \\
\text { unknown etiology }(n=44,40 \%)\end{array}$ & $14(30 \%)$ & $30(47 \%)$ & $0.50(0.22,1.1)$ \\
\hline Congenital anomaly $(n=20,18 \%)$ & $8(17 \%)$ & $12(19 \%)$ & $0.91(0.34,2.4)$ \\
\hline Infectious disease $(n=19,17 \%)$ & $12(26 \%)$ & $7(11 \%)$ & $2.9(1.0,8.0)$ \\
\hline Other/unknown $(n=22,20 \%)$ & $9(20 \%)$ & $13(20 \%)$ & \\
\hline
\end{tabular}

ancludes perinatal events $(n=4)$, drug exposure $(n=4)$, abuse or neglect $(n=3)$, preterm birth $(n=1)$, and other/unknown $(n=10)$.

Table 4 Association between the arctic variant of CPT1A and health history

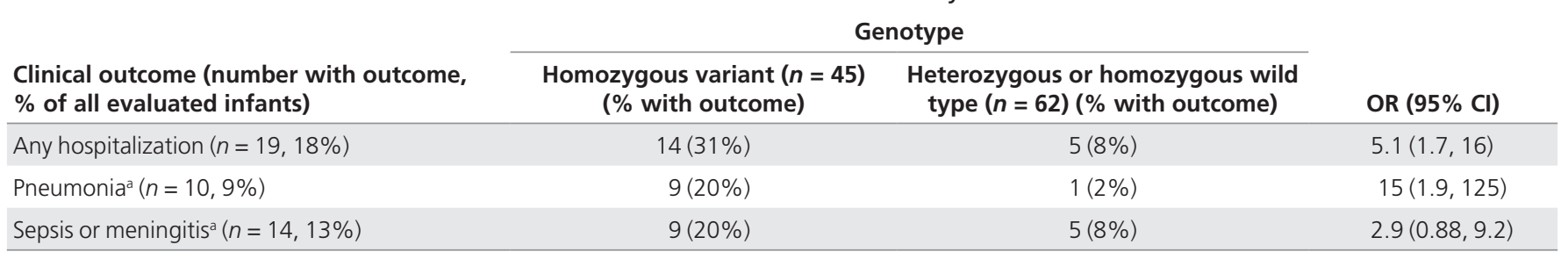

aFive of the 10 pneumonias and 12 of the 14 sepsis/meningitis episodes occurred during the newborn period. 
(unpublished analysis of Alaska Bureau of Vital Statistics data, B.D.G.). Our data indicate that, after controlling for other known risk factors, the higher prevalence of the arctic variant in western and northern Alaska is probably contributing to this increased rate of infant mortality. The previously identified risk factors for mortality controlled for in our analysis may be confounders because they could be associated with CPT1A genotype if certain populations were both more likely to have these characteristics and more likely to be homozygous. However, all of these factors could also act as effect modifiers for CPT1A genotype. For example, substance-using mothers or mothers without sufficient support from the infant's father may be less likely than other mothers to seek medical care in a timely way during episodes of illness, increasing the risk for hypoketotic hypoglycemia and death in infants with reduced CPT1A activity due to homozygosity for the arctic variant. ${ }^{7}$ These results confirm our previous report, which was based on a much smaller data set $^{13}$ and is also consistent with the known association of fatty acid oxidation disorders with infant mortality. ${ }^{8}$

The mechanism for the increased risk of infant mortality remains unknown. Based on evidence of an association between fatty acid oxidation disorders and sudden death, we expected unrecognized hypoglycemia and presentation similar to SIDS to be likely. However, homozygosity for the arctic variant was underrepresented among SIDS cases compared to other causes of death. By contrast, deaths associated with infectious disease were more likely in cases homozygous for the arctic variant, a finding we have reported previously. ${ }^{13}$ Historically, and for unknown reasons, Alaska Native infants, particularly residents of western and northern Alaska, have had among the highest incidences ever documented of severe illness due to respiratory syncytial virus, ${ }^{19,20}$ Haemophilus influenzae type $\mathrm{b},{ }^{21}$ Streptococcus pneumoniae, ${ }^{22}$ and hepatitis B. ${ }^{23,24}$ We recently reported an association between these high rates of infection and homozygosity for the arctic variant. ${ }^{25}$ Consistent with that observation, in this study we found that children with a premorbid history of a severe infectious disease (pneumonia, sepsis, meningitis) were more likely to be homozygous for the arctic variant than children who lacked such history. A possible mechanism for this association is the dependence of $\mathrm{CD}^{+}$ memory $\mathrm{T}$ cells on fatty acid oxidation. ${ }^{26}$ Impaired function of these critical immune cells as a result of reduced CPT1A activity may increase the risk of progression or the rate of progression to severe disease once infected. Independent of such a mechanism, the stress of infection in infants with reduced CPT1A activity increases the risk of hypoglycemia and other consequences, including death. ${ }^{8}$

The CPT1A arctic variant was first identified in Alaska Native infants in 2003 following the implementation of expanded newborn screening by tandem mass spectrometry. Subsequent evaluations demonstrated that the number of infants being identified by newborn screening as homozygous for the arctic variant was far lower than predicted based on its gene frequency, indicating a low rate of ascertainment. ${ }^{3}$ This led to the question of whether changes in the approach to newborn screening should be made to improve ascertainment. Opinions varied, but many felt that such a common genetic variant (allele frequency $=0.7$ ) that is in Hardy-Weinberg equilibrium within the Alaska Native population of western and northern Alaska ${ }^{3}$ was unlikely to be associated with any deleterious health effects. If this were true, then identifying and potentially stigmatizing infants homozygous for the arctic variant would be inappropriate. Similar concerns were being raised among the newborn screening communities in British Columbia and other regions of Canada, where a high prevalence of the arctic variant in the Inuit and some First Nations populations has been observed. ${ }^{2,6}$ This prompted the Maternal and Child Health Bureau of the US Health Resources and Services Administration, the American College of Medical Genetics and Genomics, and other groups to sponsor a satellite meeting (Screening for Carnitine-Palmitoyl Transferase, Type 1A (CPT1A) in First Nations Populations: A Community Conversation) at the 2011 American College of Medical Genetics and Genomics Clinical Genetics Conference in Vancouver, British Columbia, to discuss the merits of newborn screening for the arctic variant. Participants included researchers (including D.M.K. and T.W), representatives from native organizations, and parents.

Based on reports of frequent episodes of hypoglycemia and seizures from physicians caring for Alaska Native infants, and on similar symptoms among Canadian Inuit infants, ${ }^{4}$ we elected to seek further data regarding potential health effects of the arctic variant to inform decisions regarding newborn screening for the arctic variant in Alaska. Formal fasting studies of homozygous children unequivocally demonstrated a reduced ability to generate ketones via fatty acid oxidation, which in some children was also associated with symptomatic hypoglycemia. ${ }^{7}$ In subsequent studies, including the present evaluation, we have shown an association between homozygosity for the arctic variant and infectious disease-related outcomes, as well as infant mortality. ${ }^{13,25}$ Identification of infants with disorders of fatty acid oxidation via newborn screening allows for education of parents regarding the need for avoidance of prolonged fasting and has been shown to reduce morbidity and mortality. ${ }^{27}$ With an estimated 700 or more Alaska Native infants homozygous for the arctic variant born each year, any intervention that reduced the associated health risks could have a significant impact. $^{3}$ The current consensus within the AKDPH leadership and representatives from Alaska Native Tribal Health organizations is that increased ascertainment of infants homozygous for the arctic variant by newborn screening is desirable. Plans are now being made to implement changes to achieve this goal. Due to concerns with issues such as the accuracy of race coding, mixed-race parentage, and racial stigmatization, any changes in newborn screening for the CPT1A arctic variant will be implemented universally, rather than targeted at Alaska Native infants.

It is clear that homozygosity for the arctic variant can be associated with negative health outcomes, and yet, paradoxically, the arctic variant is the wild type, or "normal," form of the CPT1A gene in the affected populations, suggesting positive 
selection. ${ }^{4}$ Evidence for strong genetic selection of the CPT1A arctic variant was recently reported in a study looking for genes associated with survival in the arctic environment. ${ }^{1}$ Based on whole-genome sequence data from indigenous northeastern Siberian people, the CPT1A arctic variant was identified as the strongest candidate for positive selection, explaining its high prevalence among northeastern Siberian, Canadian, Greenland Inuit, and Yup'ik and Inupiat Alaska Native people. The basis for this positive selection is believed to be the high fat content of the traditional diet, a cold environment, or a combination of both.

The amino acid change associated with the arctic variant (P479L) results in reduced CPT1A catalytic activity and a significant decrease in sensitivity to inhibition by malonyl-CoA, which is one of the primary mechanisms by which fatty acid oxidation is suppressed when sufficient carbohydrate (glucose) is available for energy production. The expression of CPT1A and many other genes that function in fatty acid oxidation in the liver is regulated by peroxisome proliferator-activated receptor- $\alpha$ (PPAR- $\alpha$ ), a transcriptional regulator that is activated by a variety of drugs and metabolites, including $n-3$ polyunsaturated fatty acids ( $\mathrm{n}-3$ PUFAs).$^{28}$ The traditional diet of the populations in which the arctic variant is found is heavily based on marine mammals and contains high levels of n-3 PUFAs. Consuming such a diet would be predicted to increase expression of CPT1A, reducing the impact of decreased catalytic activity associated with the arctic variant. Consequently, the primary physiologic effect of the arctic variant would be the reduction of malonyl-CoA sensitivity, resulting in an increase in the basal rate of fatty acid oxidation. Although direct evidence for such an effect is lacking, it has been proposed that an interaction between a diet high in n-3 PUFA and homozygosity for the arctic variant is the basis for the "healthy obesity" phenotype in the Yup'ik and Inuit populations, which includes low triglyceride levels, reduced C-reactive protein, and high circulating HDL cholesterol. ${ }^{29-31}$ Homozygosity for the arctic variant has also been associated with reduced body fat and central adiposity, as well as increased HDL cholesterol and apolipoprotein A-I, independent of body mass index $\left(\mathrm{kg} / \mathrm{m}^{2}\right)$., 29

Our study had several limitations. Because this was a casecontrol study, we could not calculate disease rates. Therefore, for example, SIDS or other cause-specific disease rates may have been higher among infants homozygous for the arctic variant even though the relative proportion measured in our study was lower. Our sample size was relatively small, which reduced the precision of our results; nevertheless, all analyses were consistent in identifying homozygosity for the CPT1A arctic variant as an important risk factor for mortality. A small sample size also precluded evaluation of questions such as whether homozygosity for the arctic variant affected mortality preferentially at different ages.

In conclusion, we report that homozygosity for the CPT1A arctic variant is an additional risk factor for infant mortality among Alaska Native people, particularly those from northern and western Alaska. Evidence is also mounting that the high prevalence of the arctic variant in these regions is related to a selective advantage, possibly associated with consumption of a traditional diet high in n-3 PUFA. We are currently designing a study to evaluate the possible relationship between n-3 PUFA intake by mothers both prenatally and during breastfeeding, and by infants and children, as possible modifiers of the health risks associated with homozygosity for the arctic variant. We believe that increased expression of CPT1A mediated by $n-3$ PUFA could mitigate the unfavorable effects of the arctic variant on infant health, and that the apparent paradox of the high prevalence of the CPT1A arctic variant despite unfavorable health effects is the result of recent changes in lifestyles, particularly decreased consumption of a traditional diet. Consequently, we believe it may be possible to reduce the increased rates of infant mortality and infectious diseases associated with the arctic variant by simple dietary interventions.

\section{ACKNOWLEDGMENTS}

We thank members of the Alaska Native Tribal Health Consortium Health Research Review Committee for many helpful comments regarding this manuscript. We also thank Matt Hirschfeld for ongoing assistance with our studies of the CPT1A arctic variant and for reviewing the manuscript. We are grateful to Dave Sesser for retrieval and processing of newborn screening cards for DNA analysis.

This study was supported by the Eunice Kennedy Shriver National Institute of Child Health and Human Development Award R03HD060728 (principal investigator: D.M.K.) and project H18 MC-00004-11 from the Maternal and Child Health Bureau (Title V, Social Security Act), Health Resources and Services Administration, Department of Health and Human Services.

The contents are solely the responsibility of the authors and do not necessarily represent the official views of the Alaska Division of Public Health, the National Institutes of Health, the Health Resources and Services Administration, or other granting agencies.

\section{DISCLOSURE}

The authors declare no conflict of interest.

\section{REFERENCES}

1. Clemente FJ, Cardona A, Inchley CE, et al. A selective sweep on a deleterious mutation in CPT1A in arctic populations. Am J Hum Genet 2014;95:584-589.

2. Collins SA, Sinclair G, Mclntosh $S$, et al. Carnitine palmitoyltransferase $1 A$ (CPT1A) P479L prevalence in live newborns in Yukon, Northwest Territories, and Nunavut. Mol Genet Metab 2010;101:200-204.

3. Gessner BD, Gillingham MB, Johnson MA, et al. Prevalence and distribution of the $\mathrm{C.1436C} \rightarrow$ T sequence variant of carnitine palmitoyltransferase $1 \mathrm{~A}$ among Alaska Native infants. J Pediatr 2011;158:124-129.

4. Greenberg CR, Dilling LA, Thompson GR, et al. The paradox of the carnitine palmitoyltransferase type la $\mathrm{P} 479 \mathrm{~L}$ variant in Canadian Aboriginal populations. Mol Genet Metab 2009;96:201-207.

5. Rajakumar C, Ban MR, Cao H, Young TK, Bjerregaard P, Hegele RA. Carnitine palmitoyltransferase IA polymorphism P479L is common in Greenland Inuit and is associated with elevated plasma apolipoprotein A-I. J Lipid Res 2009;50:1223-1228

6. Sinclair GB, Collins S, Popescu O, McFadden D, Arbour L, Vallance HD. Carnitine palmitoyltransferase I and sudden unexpected infant death in British Columbia First Nations. Pediatrics 2012;130:e1162-e1169. 
7. Gillingham MB, Hirschfeld M, Lowe $S$, et al. Impaired fasting tolerance among Alaska native children with a common carnitine palmitoyltransferase 1A sequence variant. Mol Genet Metab 2011;104:261-264.

8. Rector RS, Ibdah JA. Fatty acid oxidation disorders: maternal health and neonatal outcomes. Semin Fetal Neonatal Med 2010;15:122-128.

9. Adams MM. The descriptive epidemiology of sudden infant deaths among natives and whites in Alaska. Am J Epidemiol 1985;122:637-643.

10. Rhoades ER, Brenneman G, Lyle J, Handler A. Mortality of American Indian and Alaska native infants. Annu Rev Public Health 1992;13:269-285.

11. Schoellhorn KJ P-HK, Goldsmith YW. Alaska Maternal and Child Health Data Book 2008: Health Status Edition. Maternal and Child Health Epidemiology Unit, Section of Maternal Child and Family Health, Division of Public Health, Department of Health and Social Services: Anchorage, AK, 2008.

12. Tomashek KM, Qin C, Hsia J, lyasu S, Barfield WD, Flowers LM. Infant mortality trends and differences between American Indian/Alaska Native infants and white infants in the United States, 1989-1991 and 1998-2000. Am J Public Health 2006;96:2222-2227.

13. Gessner BD, Gillingham MB, Birch S, Wood T, Koeller DM. Evidence for an association between infant mortality and a carnitine palmitoyltransferase $1 \mathrm{~A}$ genetic variant. Pediatrics 2010;126:945-951.

14. Blabey MH, Gessner BD. Three maternal risk factors associated with elevated risk of postneonatal mortality among Alaska native population. Matern Child Health J 2009;13:222-230.

15. Greenland S. Modeling and variable selection in epidemiologic analysis. Am J Public Health 1989;79:340-349.

16. Robins JM, Greenland S. Identifiability and exchangeability for direct and indirect effects. Epidemiology 1992;3:143-155.

17. Wilcox AJ, Russell IT. Perinatal mortality: standardizing for birthweight is biased Am J Epidemiol 1983;118:857-864.

18. Newborn screening: toward a uniform screening panel and system. Genet Med 2006;8(suppl 1):1S-252S.

19. Holman RC, Curns AT, Cheek JE, et al. Respiratory syncytial virus hospitalizations among American Indian and Alaska Native infants and the general United States infant population. Pediatrics 2004;114:e437-e444.
20. Karron RA, Singleton RJ, Bulkow L, et al. Severe respiratory syncytial virus disease in Alaska native children. RSV Alaska Study Group. J Infect Dis 1999;180:41-49.

21. Ward JI, Margolis HS, Lum MK, Fraser DW, Bender TR, Anderson P. Haemophilus influenzae disease in Alaskan Eskimos: characteristics of a population with an unusual incidence of invasive disease. Lancet 1981;1:1281-1285.

22. Davidson M, Schraer CD, Parkinson AJ, et al. Invasive pneumococcal disease in an Alaska native population, 1980 through 1986. JAMA 1989;261:715-718.

23. Barrett DH, Burks JM, McMahon B, et al. Epidemiology of hepatitis $B$ in two Alaska communities. Am J Epidemiol 1977;105:118-122.

24. Schreeder MT, Bender TR, McMahon BJ, et al. Prevalence of hepatitis B in selected Alaskan Eskimo villages. Am J Epidemiol 1983;118:543-549.

25. Gessner BD, Gillingham MB, Wood T, Koeller DM. Association of a genetic variant of carnitine palmitoyltransferase $1 \mathrm{~A}$ with infections in Alaska Native children. J Pediatr 2013;163:1716-1721.

26. van der Windt GJ, Everts $\mathrm{B}, \mathrm{Chang} \mathrm{CH}$, et al. Mitochondrial respiratory capacity is a critical regulator of CD8+ T cell memory development. Immunity 2012;36:68-78.

27. Wilcken $B$, Haas $M$, Joy $P$, et al. Outcome of neonatal screening for mediumchain acyl-CoA dehydrogenase deficiency in Australia: a cohort study. Lancet 2007;369:37-42.

28. Kliewer SA, Sundseth SS, Jones SA, et al. Fatty acids and eicosanoids regulate gene expression through direct interactions with peroxisome proliferatoractivated receptors alpha and gamma. Proc Natl Acad Sci USA 1997;94: 4318-4323.

29. Lemas DJ, Wiener HW, O'Brien DM, et al. Genetic polymorphisms in carnitine palmitoyltransferase $1 \mathrm{~A}$ gene are associated with variation in body composition and fasting lipid traits in Yup'ik Eskimos. J Lipid Res 2012;53:175-184.

30. Makhoul Z, Kristal AR, Gulati R, et al. Associations of very high intakes of eicosapentaenoic and docosahexaenoic acids with biomarkers of chronic disease risk among Yup'ik Eskimos. Am J Clin Nutr 2010;91:777-785.

31. Makhoul Z, Kristal AR, Gulati R, et al. Associations of obesity with triglycerides and $C$-reactive protein are attenuated in adults with high red blood cell eicosapentaenoic and docosahexaenoic acids. Eur J Clin Nutr 2011;65: 808-817. 